\title{
Contaminação química: respostas das instituições responsáveis e ações das populações atingidas no Brasil e em Portugal'
}

\author{
Chemical contamination: institutional responses and actions of affected \\ populations in Brazil and Portugal
}

\author{
Lúcia de Oliveira Fernandes \\ Universidade de Lisboa. Centro de Investigação em So- \\ ciologia Económica e das Organizações. Lisboa, Portugal. \\ Universidade de Coimbra. Centro de Estudos Sociais, Coimbra, \\ Portugal. \\ E-mail: luciaofœgmail.com

\section{João Arriscado Nunes} \\ Universidade de Coimbra. Faculdade de Economia. Coimbra, \\ Portugal. \\ E-mail: janळces.uc.pt

\section{Marcelo Firpo de Souza Porto} \\ Fundação Oswaldo Cruz. Centro de Estudos em Saúde do Traba- \\ Ihador e Ecologia Humana. Rio de Janeiro, Brasil. \\ E-mail: marcelo.firpoळensp.fiocruz.br
}

\section{Resumo}

A contaminação química gera poluição ambiental e problemas de saúde, entre outros impactos diretos e indiretos. 0 artigo aborda dois contextos particulares de contaminação em dois países: Brasil e Portugal. Cidade dos Meninos, no Estado do Rio de Janeiro, área rural onde houve atividade industrial no passado, sendo atualmente uma área contaminada. Estarreja, uma cidade no centro de Portugal, onde se localiza um polo químico em atividade que apresenta contaminação passada no meio ambiente por diversas substâncias tóxicas e impactos presentes de sua atividade. Este artigo apresenta uma discussão sobre áreas contaminadas e as respostas (e ausência de respostas) das instituições responsáveis pelo controle e/ou minimização dos efeitos da contaminação ambiental e humana nos níveis local, regional e nacional, e de quem vive os problemas no seu lugar de habitação e/ou trabalho. A análise assentou numa abordagem integrada relacionando os processos que costumam ser atribuídos aos domínios do "meio ambiente", da "saúde", do "social”, do “económico", do "político" e da "justiça”, mantendo atenção às especificidades de cada caso e contexto. Palavras-chave: Poluição Ambiental; Saúde; Contaminação Química; Complexidade; Incerteza; Risco.

\section{Correspondência}

Rua Miguel Lupi, 20.

Lisboa, Portugal. Código postal: 1249-078.

\footnotetext{
1 A pesquisa foi financiada pela Fundação da Ciência e Tecnologia do Ministério de Ciência, Tecnologia e Inovação (Portugal) no âmbito de uma tese de doutorado.
} 


\section{Abstract}

Chemical contamination generates environmental pollution and health problems, among other direct and indirect impacts. This article focuses on two particular contaminated contexts in two countries: Brazil and Portugal. One case is Cidade dos Meninos, in the state of Rio de Janeiro, Brazil, a rural area, where there was industrial activity in the past and currently is a contaminated area. Another case study is Estarreja, city in the center of Portugal, an active chemical industry complex with past contamination by different toxics for health and present impacts of its activity. The article discusses the actions of the affected communities and the responses (and also the lack of response) of the institutions in charge of controlling and minimizing the effects of contamination in the local, regional and national levels. The analysis is based in an integrated approach relating processes usually separated into the domains of "environment," "health," "social," "economics," "politics" and "justice," while maintaining close attention to the specificities of each case and context.

Keywords: Environmental Pollution; Health; Chemical Contamination; Complexity; Uncertainty; Risk.

\section{Introdução}

O problema das áreas contaminadas nos países mais ricos e industrializados do mundo tornou-se público principalmente a partir dos anos 1970, através de dois casos: Love Canal, nos Estados Unidos da América (EUA) e Lekkerkerk, na Holanda (Sánchez, 2004). Em ambos os casos, habitações foram construídas sobre lixeiras de resíduos industriais. 0 caso de Love Canal impulsionou o avanço, nos anos 1980, nos EUA, da elaboração de uma legislação para descontaminação de solos, o Comprehensive Environmental Response Compensation and Liability Act, e um desenho de procedimentos administrativos que responsabilizam os poluidores. Um dispositivo, denominado Programa Superfund, foi criado para desenvolver ações de descontaminação, baseando-se em três critérios para decisão das ações a serem desenvolvidas sobre um caso de contaminação: a presença de substâncias químicas perigosas, a existência de pessoas expostas diretamente aos contaminantes e o número de pessoas nessa situação. Não sendo possível atribuir responsabilidade pela contaminação, o próprio fundo arca com as despesas das ações necessárias. Em 1992, 36 mil sítios contaminados foram reportados à Environmental Protection Agency (Hamilton; Viscusi, 1999, p. 15).

No Brasil, a Companhia de Tecnologia de Saneamento Ambiental (Cetesb) foi a primeira agência ambiental a atuar sobre o tema. Em 2002, iniciou um inventário de áreas contaminadas, e em 2009 divulgou o número de 4.131 áreas (Brasil, 2009). Em 2004, a Secretaria de Vigilância Sanitária (SVS) do Ministério da Saúde (MS) criou o Programa de Vigilância em Saúde das Populações Expostas a Solo Contaminado (Vigisolo) com o objetivo de implementar ações sobre a prevenção e o controle da exposição ao solo contaminado. Este programa foi substituído pelo Sistema de Informação de Vigilância em Saúde de Populações Expostas a Solo Contaminado (Sissolo). As suas principais áreas de atuação são: identificação de áreas com populações (potencialmente) expostas ao solo contaminado, priorização das áreas mais críticas para atuação, avaliação do risco de exposição e desenvolvimento de protocolos de vigilância e atenção à saúde das populações. Não há muitos dados pú- 
blicos recentes sobre o assunto. Há dados do período 2001-2008 dos estados e municípios que apontam que 2,1 milhões pessoas vivem potencialmente expostas a contaminantes químicos, residindo em uma das 2.527 áreas com solo contaminado identificadas no Brasil (Portal Saúde, 2009). O Ministério do Meio Ambiente (MMA) publicou uma legislação nacional que regula a qualidade do solo quanto à presença de substâncias químicas e estabelece as diretrizes para o gerenciamento ambiental de áreas contaminadas, a Resolução Conama 420/o9.

Já em Portugal não existem políticas públicas dirigidas aos casos de contaminação, nem legislação específica para a qualidade dos solos. Em 2007, foi criado o Grupo de Trabalho Passivos Ambientais, através do Despacho 28176/2007, de 14 de Dezembro, do Ministério do Ambiente e Ordenamento do Território (MAOTDR) e do Ministério da Economia e da Inovação, com o objetivo de definir as ações no domínio da reabilitação de áreas degradadas pelos efeitos da indústria extrativa e de passivos ambientais, constituídos por sítios e solos contaminados em áreas industriais abandonadas ou desativadas. Não há estudos públicos realizados pelas instituições responsáveis sobre a contaminação química existente no país; há apenas estudos académicos de diferentes áreas científicas que abordam aspetos específicos sobre a contaminação das águas, dos solos e do ar em áreas contaminadas por atividades industriais, mineiras, rurais e pela existência de lixeiras. Segundo Panagos et al. (2013), Portugal é um dos cinco países europeus (junto com Bósnia-Herzegovina, Polónia, Eslovénia e Turquia) que não responderam ao inquérito realizado em 2011-12, pelo European Soil Data Center da União Europeia (UE).

Na UE², em 1994, realizou-se o Common Forum for Contamination, com o objetivo de aprofundar o conhecimento da situação de cada Estado-membro em relação às áreas contaminadas, identificar áreas temáticas para cooperação entre os países e integrar a UE em ações internacionais já existentes. Em 1996, foi criado o projeto Concerted Action on Risk Assessment for Contaminated Sites, dentro do Programa de Ambiente e Clima da UE, que desenvolveu estudos sobre as áreas contaminadas em 16 países europeus (Ferguson, 1999). Em 2006, surgiu a Estratégia Europeia de Proteção do Solo, documento que tinha como objetivo impulsionar uma política europeia para a proteção dos solos, que não foi até hoje consolidada, por causa de divergências entre as visões dos atores industriais, estatais e da sociedade civil. Segundo Panagos et al. (2013), há 2,5 milhões de potenciais áreas contaminadas e 342 seguramente contaminadas nos 33 países da Europa que responderam ${ }^{3}$.

Os estudos académicos aprofundados sobre os casos de contaminação química (em locais onde pessoas habitam/trabalham), chamadas por Edelstein (2004) de "comunidades contaminadas", focam-se em situações nas quais os afetados foram removidos, compensados ou em que o local foi descontaminado (Auyero; Swistun, 2009). Como exemplos podemos citar o estudo de Brown e Mikkelsen (1997) sobre o caso de Woburn, Massachussets, onde a população conseguiu indenizações dos poluidores; o caso de Love Canal, em que a remoção da população e as compensações foram realizadas (Levine, 1982); e os casos localizados no denominado "corredor químico", na Louisiana, onde os impactados tiveram também sucesso, conseguindo compensações (Allen, 2003). O estudo de Auyero e Swistun (2009) sobre o caso de Flammable, na Argentina, é o único a abordar um contexto de contaminação onde a população permanecia até aquela data no local, e as medidas tomadas pelas autoridades para resolver a contaminação eram escassas. Os casos de contaminação que serão apresentados neste artigo têm esta mesma característica, criando-se comunidades contaminadas, desassistidas e invisíveis.

Apresentamos neste artigo $^{4}$ uma discussão sobre áreas contaminadas e as respostas (e ausência de

2 É importante referir o contexto europeu, já que Portugal pertence à UE.

3 Uma estimativa subdimensionada, já que os cinco países europeus que não responderam ao inquérito são países com políticas públicas menos abrangentes sobre o assunto e em situação de maior vulnerabilidade económica, social e política.

4 Resultados da pesquisa desenvolvida para a tese de doutorado: "Complexidade, incertezas e vulnerabilidades: estudo de áreas contaminadas habitadas em Portugal e no Brasil”, finalizada no ano de 2011 no Programa Doutoral “Governação, Conhecimento e Inovação” da Faculdade de Economia e do Centro de Estudos Sociais da Universidade de Coimbra (com colaboração do Centro de Estudos da Saúde do Trabalhador e Ecologia Humana, da Escola Nacional de Saúde Pública, Fiocruz) (Fernandes, 2011). 
respostas) das instituições responsáveis pelo controle e/ou minimização dos efeitos da contaminação ambiental e humana e de quem vive os problemas no seu lugar de habitação e/ou trabalho. Os casos estudados foram a Cidade dos Meninos (CM), área industrial desativada e contaminada, no estado do Rio de Janeiro, e Estarreja, um polo químico em Portugal com problemas de contaminação passados e presentes 5 .

\section{Complexidade e incertezas: aspetos centrais da contaminação química}

A contaminação química situa-se em vários domínios: do "meio ambiente", da "saúde", do "social", da "justiça”, do "económico", do "político", e inclusive de outros domínios abstratos e simbólicos. Essas diferentes faces do problema são parte de sua complexidade e são geralmente tratadas separadamente, pouco articuladas e/ou simplesmente esquecidas ${ }^{6}$.

A mudança do papel atribuído à natureza nas sociedades industrializadas contribui para a separação do tratamento das questões do meio ambiente e da saúde. Em sociedades pré-capitalistas ou tradicionais, a natureza era encarada como o sustento da vida, havendo relações de completa interdependência entre as sociedades humanas e todos os elementos naturais do seu entorno (Shiva, 1992). Atualmente, a natureza é vista como algo externo aos seres humanos, como uma ferramenta do desenvolvimento, um recurso para a produção de bens e para o crescimento das economias. A natureza, a comunidade e sua realidade diária não são vistas como indissociáveis (Levins; Lopez, 1999). A saúde é avaliada apenas como ausência de doença e/ou boa disposição física e psíquica, como refere Porto (2012), e o ciclo constituído pela geração dos riscos, exposição dos indivíduos e efeitos à saúde provocados pela contaminação não são analisados de forma ampla e com outros aspetos do problema.

O alargamento do uso de químicos sintéticos e o crescimento deste sector industrial originaram o aumento e a diferenciação dos riscos existentes. 0 grande número de substâncias e de fontes de exposição aumentam as incertezas na previsão dos efeitos dos químicos sobre o meio ambiente e a saúde das populações e dos trabalhadores.

É importante ter uma visão crítica a respeito da ausência de informação sobre os dados produzidos a respeito da toxicidade, das substâncias e da ausência de informação a este respeito em vários casos, bem como da invisibilização das comunidades contaminadas, que refletem uma ampliação da incerteza global existente. Pode-se destacar alguns fatores de natureza física, química e biológica que contribuem para esta situação: a exposição a múltiplas substâncias (a interação entre elas pode resultar em novos compostos tóxicos), rotas de exposição variadas (cadeia alimentar, leite materno, solo, água, ar, ambiente de trabalho, moradia e lazer), diferenciados estados clínicos dos cidadãos e das populações, fatores genéticos, entre outros. Além disso, processos de origem social, económica, política e cultural influenciam tais fatores.

Apenas para exemplificar o elevado grau de incerteza presente nas previsões dos efeitos dos químicos na saúde e no meio ambiente, apresentam-se alguns dados disponíveis na literatura:

- No final da década de 1980, já eram referidas 70 mil substâncias químicas conhecidas em todo o mundo e apenas 6 mil tinham sido bem avaliadas quanto aos riscos que comportavam (Wynne, 1987). Nessa data, apenas entre 1,5 e $3 \%$ dos produtos químicos que circulavam no mercado foram testados quanto a suas propriedades cancerígenas (Steingraber, 1998, p. 99).

50 trabalho de campo foi desenvolvido entre 2006 e 2010. Foi realizado o acompanhamento presencial e documental das ações desenvolvidas pelas populações e pelas instituições públicas e privadas sobre a contaminação e temas afins nos dois locais. Foi também realizada a recolha de documentos diversos (relatórios científicos, técnicos, institucionais, material de imprensa, atas de reuniões e notícias), a participação em reuniões e fóruns, entrevistas, depoimentos informais e de workshops, que se constituíram como principais fontes de dados.

6 É importante assumir que à partida não sabemos quais são todas as dimensões importantes dos problemas. Destaca-se neste ponto a importância dos estudos qualitativos como este, que ouvem as pessoas afetadas pelos problemas, tomam conhecimento do contexto local e acompanham os fóruns existentes para articulação dos diferentes atores. 
- Para analisar a sinergia entre 25 químicos de forma rigorosa, seriam precisos cerca de 33 milhões de ensaios de toxicidade (Thornton, 2000, p. 83).

Para reduzir esse tipo de incerteza, mais testes específicos poderiam ser realizados. Porém, o segundo dado mostra-nos a impossibilidade de um estudo que dê conta dos efeitos dos diversos químicos tóxicos a que estamos expostos na nossa rotina em casa, no trabalho e no lazer, e suas interações, pois são muito mais de 25 as substâncias que estão presentes em produtos de higiene, limpeza, têxtil, bens de consumo etc.

Incertezas estarão sempre presentes, independentemente do conhecimento científico que for produzido. 0 saber científico apresenta limitações na elaboração de uma descrição da complexidade da realidade através das metodologias e dos modelos que formula e aplica para a descrição dos fenómenos. Além disso, há também uma influência direta das opções individuais dos cientistas e dos técnicos por metodologias/modelos no decorrer do estudo destas questões. Reconhecer e enfrentar a incerteza é muito importante, e é indissociável da abertura da discussão dessas questões com a sociedade civil. 0 próprio conceito de incerteza, tal como entendido e utilizado nos trabalhos de cientistas e de peritos, assume significados diversos, associado a seus diferentes componentes. Funtowicz e Ravetz (1993) propuseram uma classificação dessas componentes da incerteza: 1) a incerteza técnica, relacionada com a inexatidão dos dados; 2) a incerteza metodológica, relacionada à não fiabilidade na análise dos dados; e 3) a incerteza epistemológica, que coloca em evidência a lacuna existente entre o conhecimento já produzido e a capacidade de analisar a evolução do problema em causa. Todos os tipos de incerteza permanecem no conhecimento produzido e, no caso da incerteza epistemológica, existem situações que nunca poderão ser totalmente desvendadas ou reduzidas. Van der Sluijs et al. (2005) complementaram esta classificação, propondo mais uma componente da incerteza, denominada incerteza societal, relacionada com a robustez social do conhecimento, isto é, a aceitação pelas pessoas do conhecimento produzido e suas diferentes interpretações da informação (o que está diretamente relacionado aos diferentes objetivos, interesses e valores do entendimento de um problema).

\section{Vulnerabilidades ou (des)igualdades de risco?}

As abordagens dominantes dos processos de decisão na área ambiental estão fortemente ancoradas na noção de igualdade perante o risco, que se inspiram na teoria da sociedade de risco desenvolvida por Ulrich Beck (1992). A ferramenta mais utilizada para o diagnóstico e o planejamento de ações sobre os problemas é a avaliação de risco quantitativa, que não considera as particularidades de exposição dos diferentes grupos e indivíduos. Segundo a teoria de Beck, a localização, o nível de vida e de segregação social e espacial seriam indiferentes na exposição generalizada aos riscos.

O conceito de vulnerabilidade social é um conceito-chave para as discussões dos casos de contaminação química que produzem impactes diretos na vida de cidadãos, e para o desenvolvimento de uma análise crítica das relações de poder patentes nos problemas que relacionam ecologia e sociedade, como sucede nas áreas contaminadas. A vulnerabilidade social, aplicada na discussão dos casos de contaminação química, designa tanto os processos responsáveis, quanto as características das populações e das regiões que enfrentam maiores dificuldades em absorver os impactes decorrentes de diferentes eventos de risco (Winchester, 1992). Esse conceito representa uma categoria empírica e uma ferramenta para os processos de decisão, já que as vulnerabilidades podem ser uma ameaça maior à saúde das populações do que os próprios riscos. Podemos dividi-lo em dois subconceitos: vulnerabilidade populacional e vulnerabilidade institucional (Porto; Fernandes, 2006).

A vulnerabilidade populacional carateriza-se pela existência de grupos populacionais expostos a situações de risco cujas condições gerais de vida e de trabalho são bastante precárias. Isso ocorre, por exemplo, em função da inexistência de serviços básicos de saneamento, de saúde e de educação, dos baixos e 
instáveis rendimentos familiares, da inexistência de canais fluídos de comunicação com as instituições públicas, da falta de acesso à informação e aos processos decisórios, e da existência de problemas sociais, como a criminalidade, que prejudicam as condições de vida e a capacidade de organização da população.

Já a vulnerabilidade institucional diz respeito ao funcionamento insuficiente ou inadequado dos mecanismos da sociedade para atuarem na promoção, prevenção e controlo dos riscos. Tais deficiências podem estar presentes tanto na formulação como na implementação de políticas públicas, na atuação de comités e fóruns de discussão, nas legislações e normas vigentes e ainda nas atividades de fiscalização (Porto; Fernandes, 2006).

Para evitar uma visão desconectada e despolitizada de categorias como vulnerabilidade e grupos vulneráveis, autores como Acselrad (2010) e Porto (2011) ressaltam a centralidade de entender os processos de vulnerabilização para resgatar a condição de sujeitos políticos e portadores de direitos das populações que vivem injustiças ambientais e fazem parte dos grupos vulnerabilizados por esses processos. Portanto, assumir a condição de vulnerabilizados pressupõe uma postura mais ativa e politizada diante da compreensão dos processos sociais, políticos e económicos que produzem iniquidades e injustiças, as quais são enfrentadas pela organização comunitária e articulações em redes mais amplas.

\section{Áreas contaminadas no Brasil e em Portugal}

\section{Cidade dos Meninos (CM)}

Localiza-se em Duque de Caxias, estado do Rio de Janeiro. Ocupa uma área de cerca de 19.416 milhões de $\mathrm{m}^{2} \mathrm{e}$ pertence, desde 2002, à União Federal. Ali funcionou, entre os anos 1920 e os anos 1990, o
Centro de Promoção Social Abrigo Cristo Redentor ${ }^{7}$, um abrigo para menores desfavorecidos. Além das crianças e dos jovens que lá residiam, o local era também residência dos funcionários e suas famílias. Tanto os menores internos como os funcionários criavam animais e praticavam uma agricultura e pecuária de subsistência, havendo ainda algumas áreas alugadas a outros produtores.

Em 1946, alguns pavilhões desse centro foram utilizados para a implantação de uma fábrica para a produção de hexaclorocicloexano ${ }^{8}$, usado para a erradicação de doenças endémicas pelo Instituto de Malariologia, do antigo Ministério da Educação e Saúde. Em 196o, ao desativar completamente a infraestrutura, foram deixados produtos tóxicos no local.

Em 1988, alguns jornais denunciaram que cerca de 400 toneladas de substâncias tóxicas estavam armazenadas a céu aberto. Muitas toneladas do produto foram manipuladas pelos moradores, que as ofereceram a amigos e familiares, ou para venda em feiras livres, já que serviam para combater ratos, piolhos e bichos da madeira. A antiga Fundação $\varepsilon_{s}$ tadual de Engenharia do Meio Ambiente (FEEMA) e a SVS do MS removeram o contaminante à superfície do solo e, alguns anos depois, cercaram e colocaram uma placa de sinalização no local, assinalando a contaminação, o que não impede, até hoje, a entrada de pessoas e de animais. Foram encontrados outros locais contendo grande quantidade dos produtos tóxicos e uma nova remoção de solo foi realizada.

Com vista à minimização do problema, ocorreu ainda o encerramento do abrigo em 1996 - que na época tinha 650 crianças alojadas ${ }^{9}$ - e das escolas locais, e a remoção de 14 famílias que viviam mais próximas dos locais com maiores concentrações de contaminantes. O MS contratou uma empresa para a descontaminação da área, que provocou, ao contrário, o agravamento do problema em termos de aumento da área contaminada e de aumento do número de contaminantes existentes. Algumas

7 Com o fim do Estado Novo, o nome alterou-se para Fundação Abrigo Cristo Redentor (FACR). Passou a receber apenas meninos e a ser chamada de CM. Em 1987, a Legião Brasileira de Assistência (LBA) incorporou a FACR ao seu património. Com sua extinção, em 1995, a área passou para a administração da Secretaria de Estado de Assistência Social do Ministério da Previdência e Assistência Social (MPAS).

8 A fábrica também produzia uma substância intermediária do processo de fabrico do DDT e fazia a mistura de HCH e DDT.

9 Não há ainda um inventário completo das pessoas que passaram pela FACR ao longo de toda sua história. 
famílias, residentes dentro e próximas da área foco, foram removidas, num primeiro momento, para imóveis alugados no centro de Duque de Caxias. Outras famílias foram removidas mais tarde e tiveram que passar a viver em condições precárias dentro das antigas instalações da Fundação.

Desde 1990, o Ministério Público Federal abriu inquéritos para investigar a contaminação. Em 1993, o MS assumiu formalmente a responsabilidade pela contaminação, através da assinatura do Termo de Ajuste de Conduta e de Obrigações, com outras instituições, como a Fundação Oswaldo Cruz (Fiocruz) e FEEMA, que iriam conjuntamente resolver os problemas. 0 termo não estava sendo cumprido e foi substituído por um plano de ação, em 2006, que por sua vez não teve a maior parte dos seus objetivos cumpridos até hoje, nem ações de responsabilização das instituições incumpridoras.

Instituições municipais, estaduais e federais e as instâncias judicial, executiva e legislativa têm responsabilidades diferenciadas e discordantes sobre o caso. Diversas instituições participaram de comissões técnicas, comités técnicos, grupos de trabalho e planos de ação, por exemplo: MS - Coordenação Geral de Vigilância em Saúde Ambiental, Fundação Nacional de Saúde, Secretaria Estadual de Saúde do Rio de Janeiro, Secretaria Municipal de Saúde de Duque de Caxias, Fiocruz e Instituto Nacional do Câncer (Inca); MMA; MPAS, Secretaria de Património da União, LBA; Procuradoria-Geral da República; Ministérios Públicos - Estadual do Rio de Janeiro e Federal - e diferentes varas de justiça federais e estadual; Governo do estado do Rio de Janeiro - FEEMA; Prefeitura de Duque de Caxias, universidades - Pontifícia Universidade Católica do Rio de Janeiro, Universidade Estadual de Campinas (UNICAMP), Universidade Federal do Rio de Janeiro.

A expressão "assombrada pelo perigo que se espalha com o vento" foi utilizada em jornais nos anos 1990, já que o solo contaminado não estava coberto e os contaminantes se espalharam pela ação das intempéries e através da movimentação diária das pessoas pela única estrada de acesso local, não asfaltada e contaminada. "Interditada ao progresso", outra expressão utilizada nos anos 2000 pela mídia, indica o isolamento do local, cujo acesso é feito por via de uma única estrada precária, com transporte público irregular, não tendo serviço de limpeza, com iluminação pública deficiente, e marcada ainda pela ausência de escolas.

Existem relatórios técnicos e estudos académicos que apontam que na CM o solo, alguns alimentos cultivados, o leite, a pastagem e a água estão contaminados, considerando-os aspetos centrais do problema. Em 2002, os resultados dos estudos de avaliação de risco à saúde classificaram a área na categoria de perigo urgente para a saúde pública, afirmando a necessidade da remoção de toda a população do local.

Em 1990, iniciaram-se alguns estudos da monitorização da saúde dos moradores que permaneceram na área ${ }^{10}$. 0 cheiro forte na estrada e os casos de deformações fetais e de câncer não foram utilizados como indícios da existência de efeitos presentes da contaminação e não foram incorporados saberes locais sobre o problema. Há vários grupos potencialmente afetados pela contaminação que foram inventariados em 2002 pelo $\mathrm{MS}^{11}$, mas as ações de acompanhamento de seu estado de saúde e a avaliação de sua relação com a contaminação só são realizadas para o grupo dos antigos funcionários da fábrica e do abrigo.

A Associação de Moradores e Amigos de Cidade dos Meninos é uma organização de cidadãos que acompanha o problema de forma permanente, mas não é unificadora dos anseios e das expectativas dos afetados. Surgiu nos anos 1980, quando o conflito fundiário na área tornou-se relevante, com tentativas de despejo de algumas famílias de antigos funcionários do abrigo. 0 fato de o centro decisor

10 A Fiocruz, o Inca, a Unicamp e a UFRJ realizaram estudos, mas sem continuidade. Alguns estudos foram invalidados com justificativa de que não seguiram protocolos técnicos e os seus resultados não são públicos. Outros foram estruturados de forma que o conhecimento anterior não fosse incorporado.

11 Famílias residentes na área: 380 (segundo dados recolhidos no trabalho de campo; este número terá aumentado para 750 até 2006); moradores do Bairro Santa Isabel situado na proximidade: 4.500 pessoas; as invasões periféricas ao longo do canal do Pilar e rio Capivari: 70 famílias; os ex-trabalhadores da fábrica de inseticidas não residentes na zona; os ex-internos da FACR (que vivem em vários estados do Brasil). 
ser em Brasília, de as instituições competentes para as diferentes matérias se localizarem em diferentes locais (Rio de Janeiro, Duque de Caxias e Brasília), e de os afetados estarem situados em Duque de Caxias, mais precisamente no interior da localidade, são aspetos que dificultaram sua luta. As pessoas afetadas desenvolveram algumas ações sobre o assunto, desde a denúncia, mas só puderam participar oficialmente de um dos grupos de trabalho ${ }^{12}$ formados para tentativa de solução para o caso, em 1994. As instituições responsáveis pelo tratamento da contaminação recolheram dados para tentar mapear melhor o problema e comunicaram, ao longo do tempo, resultados de estudos à associação, mas nunca a consideraram uma verdadeira parceira para a estruturação da solução.

O Estado brasileiro, representado pelo MS, foi o agente poluidor da área e pode ser considerado, de certa forma, negligente em relação às ações que tem empreendido para resolver o problema. A iniciativa de convidar famílias para viverem no local partiu de uma instituição, a FACR (inicialmente privada e depois convertida em pública), a mesma instituição que permitiu a instalação da indústria responsável pela poluição da área. A decadência dessa instituição e de sua memória, com a promulgação do Estatuto da Criança e do Adolescente, a extinção da LBA e, mais tarde, a deflagração da contaminação, ocasionaram o início e a continuidade dos problemas decorrentes da contaminação. A construção do arco metropolitano da rodovia RJ-109, de uma zona especial de exportação, a passagem de mais condutas da Petrobras e os projetos de habitação da Prefeitura Municipal de Duque de Caxias são projetos que existem para a área.

\section{Estarreja}

Estarreja localiza-se na região Centro de Portugal e faz parte do ecossistema da Ria de Aveiro, uma laguna integrante da zona húmida mais importante do país. Aárea é classificada como Reserva Ecológica Nacional e Zona de Proteção Especial para Aves, o que fez que fosse integrada na rede ecológica europeia. A região possui uma beleza natural relevante, indústrias químicas principais ${ }^{13} \mathrm{e}$ a região do Baixo Vouga Lagunar, que fazem parte da Ria de Aveiro.

Desde 1930, várias indústrias começaram a se instalar a cerca de $1 \mathrm{~km}$ do perímetro urbano da cidade. Atualmente, o complexo químico de Estarreja é o terceiro polo químico mais importante do país, contando com cinco indústrias químicas principais $^{14}$. No passado, havia produção de matérias-primas para a produção de adubos (sulfato e nitrato de amónio, principalmente), que foram encerradas. As células de mercúrio eram utilizadas no processo de produção de cloro e soda, tendo sido substituídas pelas células de membranas. Havia também uma fábrica de produção de ácido sulfúrico e hidrogénio, que fechou. Atualmente há produção de resinas de PVC, através do cloreto de vinila, do acetileno e nitrobenzeno, de anilina, clorobenzeno, através do benzeno, metil-di-iso-cianato, que utiliza o gás fogénio na sua produção, poliestireno extrudido, entre outros. Entre os anos 1950 e 1980, as indústrias eram o sector dominante da oferta de emprego local, uma situação que, desde 1985, se alterou substancialmente. A agricultura e a pecuária continuam a vincular os residentes à terra e a reproduzir uma relação material e simbólica fundamental para sua identidade. A produção de carne de vaca e leite e o plantio de milho e batata são predominantes nestes setores. A pesca também é uma atividade local relevante.

Entre sua fundação, nos anos 1930, e o início do século XXI, as indústrias utilizaram o meio ambiente (solos, água e ar) como recetor de seus resíduos brutos. Em 2005, foi inaugurado um aterro para resíduos industriais perigosos para substituir três depósitos de resíduos sólidos tóxicos e perigosos sobre um solo local arenoso a céu aberto, que totalizavam 250-30o mil metros cúbicos. As indústrias conduziam seus efluentes líquidos, uma mistura de mercúrio, arsénico, chumbo, zinco, ferro, anilina, amónia, benzeno

12 Grupo de Trabalho, Portaria 233, 28/o1/1994. A principal ação desenvolvida foi a vedação da maior área de concentração de resíduos (foco principal de contaminação).

13 Um braço estreito do mar que se estende pela terra.

14 Dow Chemical, Air Liquide (empresas multinacionais), Cires e CUF Químicos Industriais. 
e seus derivados, para três valas a céu aberto, que atravessam terrenos agrícolas e pastagens. Em 1989, era possível ver a olho nu as descargas de gases no ar, estimadas em vinte toneladas de gases tóxicos por dia, sendo levados para outros lugares com o vento predominante de Norte e a ausência de vales para contê-los.

As manchetes dos jornais nos anos 1990 ("Que tipo de morte ali dormirá?", "Um barril de pólvora” ou "Um vulcão") descrevem a preocupação com alguns dos impactos da atividade industrial para o meio ambiente e a saúde das populações. Existem alguns estudos que diagnosticaram aspetos do problema de poluição ambiental desde os anos 1990, mas não há um diagnóstico global da contaminação e dos riscos para a saúde, nem estudos sobre os riscos da atividade industrial atual. Os principais contaminantes presentes no meio ambiente são: chumbo, mercúrio, níquel, cobre, arsénico, zinco, cádmio, monocloretos, amónio, aminas aromáticas, monóxido de carbono, dióxido de enxofre, óxido de azoto, benzeno, nitrobenzeno, clorobenzeno, cloreto de vinila e PVC. O peixe contaminado, a morte de animais, a dificuldade de plantio, o cheiro forte na água e no ar e o mal-estar de várias pessoas aparecem em relatos dos habitantes locais, que revelam que a contaminação local gera efeitos nocivos para a saúde e o meio ambiente.

As instituições competentes possuem, portanto, desde longa data, informações dispersas sobre os problemas, mas não existe um plano de ação efetivo para resolver a situação de forma abrangente. Até hoje, felizmente, não ocorreu nenhum grande desastre ambiental, nem nenhum acidente classificado como grave. Há diferentes instituições locais, regionais e nacionais com alguma atuação sobre esta questão: o MAOTDR (especificamente a Comissão Cooperação Regional do Centro e Associação
Portuguesa de Ambiente), Autoridade Nacional de Proteção Civil (da qual atuaram os Bombeiros de Estarreja e de outras localidades próximas), Câmara Municipal de Estarreja ${ }^{15}$, o Laboratório Nacional de Engenharia Civil, a Universidade de Aveiro e a UE ${ }^{16}$.

O histórico de constituição do polo químico, com algumas empresas de capital público, facilitou uma relação de proximidade entre as empresas e as instituições locais, regionais e centrais responsáveis pela fiscalização e controlo da atividade industrial, criando "uma responsabilidade compartilhada" entre o Estado e as indústrias com relação ao controle dos processos industriais e seus efeitos. É transmitida uma imagem de que os problemas existentes são dispersos, de baixa intensidade e decorrentes das atividades industriais do passado. Mas a atividade atual das indústrias também contribui para a contaminação ambiental. Apesar da mudança das práticas industriais referentes ao meio ambiente e à segurança, há ainda queixas das populações sobre descargas de substâncias para os ecossistemas, poluição da água e dos solos, efeitos na biodiversidade e na saúde dos cidadãos. Mecanismos de responsabilização das empresas pelos episódios de poluição presentes e passados previstos nas normas em vigor não têm sido postos em prática.

Em 2001, as empresas constituíram um painel consultivo $^{17}$ que conta com a participação de diversas instituições ${ }^{18}$. Esse fórum contribui para a reafirmação da aceitação da atividade industrial e tentativa da melhoria da sua imagem, não sendo um espaço de participação dos atores sobre as questões locais relacionadas à indústria química.

A população de Estarreja encontra-se muito exposta à contaminação através dos diferentes meios, principalmente os solos, a água e a cadeia alimentar.

\footnotetext{
15Câmara municipal é a denominação utilizada em Portugal para o órgão executivo de cada município, constituído por vários departamentos e serviços da administração municipal. Tem funções semelhantes às prefeituras brasileiras.

16 Financiou parte da construção do aterro para resíduos perigosos.

17 No âmbito das ações do Programa Atuação Responsável, iniciativa da indústria química mundial que visa melhorar o desempenho das empresas nas áreas de ambiente, de saúde e de segurança.

18 Uma empresa de transportes de produtos químicos, a Associação Portuguesa das Empresas Químicas, os Bombeiros Voluntários de Estarreja, o hospital, o centro de saúde, a Guarda Nacional Republicana, uma associação empresarial local, três agrupamentos escolares e uma escola secundária, o Departamento de Ordenamento e Ambiente da Universidade de Aveiro, a ONGA Cegonha e a Associação de Moradores da Urbanização da Póvoa de Baixo.
} 
O fato de os cidadãos estarem expostos a uma contaminação permanente e crónica não levou a uma reação de protesto, de indignação e de reivindicação dos seus direitos. Não há associações locais com uma atuação permanente sobre a contaminação química, havendo ações em alguns momentos críticos, uma forma de resposta aos episódios de poluição agudos e acidentes ${ }^{19}$. Apenas houve pedidos individuais às empresas para o acesso à água própria para consumo e de compensações monetárias, através do reembolso do valor gasto com a conta de água, que não se alargaram para o âmbito da justiça. Os sindicatos e os coletivos de trabalhadores também não se mobilizaram.

Os cidadãos avaliam que a operação industrial gerava muitos mais efeitos negativos no passado do que hoje, mas não deixam de perceber os efeitos que ficaram da contaminação passada. A ênfase fica, no entanto, colocada nos benefícios da atividade da indústria, considerada única opção para a economia local, e que não aparece como causa ou origem dos problemas. As indústrias foram, no passado, financiadas por capital público, o que coloca o Estado também na posição de um dos (vários) agentes poluidores. A dependência da população em relação às empresas é muito alargada, já que mesmo famílias que não tenham membros a trabalhar nelas podem trabalhar em atividades que dependem da indústria. Estes são fatores importantes para explicar a falta de mobilização coletiva local e as vulnerabilidades populacionais.

\section{Discussão}

A integração das discussões dos dois casos e o recurso aos conceitos apresentados permitiu sistematizar algumas conclusões gerais e particulares sobre as duas realidades.

Os riscos existentes apresentam características semelhantes. A contaminação dá-se por diversos contaminantes, com potenciais efeitos graves para a saúde, por várias vias de exposição (solo, água, ar, leite materno etc.). A água é utilizada para rega, portanto é uma forma de propagação da contaminação para fora dos locais contaminados. 0 fato de os locais contaminados estarem acessíveis para o cultivo, a criação de animais e também para a circulação de pessoas, é outra forma de aumentar a influência da contaminação.

As incertezas têm também aspetos comuns. De forma geral, há incertezas nas previsões existentes de como as diversas substâncias interagem entre si e de como são os seus efeitos individuais e combinados sobre o meio ambiente e a saúde. 0 alcance e as consequências da contaminação pela via da cadeira alimentar são aspetos com muita incerteza agregada, que não são assumidos como tais. Não há estudos abrangentes sobre a contaminação dos alimentos em nenhum dos dois locais. Ou seja, apesar da complexidade dos problemas de contaminação que podem envolver incertezas epistemológicas, existem incertezas técnicas e metodológicas que poderiam ser reduzidas. A primeira pela sistematização de dados sobre a contaminação ambiental e indicadores de saúde, e a segunda através da trabalhos integrados entre várias áreas de conhecimento como a avaliação de riscos, a ecotoxicologia e a epidemiologia. Tais especialidades, contudo, quando existentes, atuam de forma fragmentada em instituições diversas sem uma adequada sistematização e análise, inclusive instituições universitárias por meio de projetos de investigação isolados. A inexistência de tais atividades de articulação, que poderiam ser realizadas por algum ator público de maior confiança e responsabilidade, somada à dificuldade de fóruns com debates e participação dos vários atores envolvidos, em especial as comunidades atingidas, intensifica outra incerteza - a desconfiança dessas comunidades em instituições e processos decisórios confiáveis (incerteza societal).

A contaminação química afeta o ambiente e a saúde em dois territórios com populações com forte ligação e sentimento de pertença ao lugar (Escobar, 1993). O vínculo antigo ao lugar, um sentimento de pertença e enraizamento, em diferentes sistemas (simbólicos, históricos e culturais), é um fator que contribui para a complexidade de enfrentar os problemas e a permanência ou não das populações nos locais contaminados. As populações vivem um dilema em seu dia a dia: poderão ter problemas de saúde futuros ao viverem no local onde nasceram e cresceram, beneficiando sua qualidade de vida pre- 
sente. Em CM, o que motiva este comportamento é o fato de continuarem a viver num lugar calmo, rural e longe dos problemas de violência generalizados na Baixada Fluminense. Em Estarreja, o pagamento da despesa de consumo individual da água pelas empresas, a garantia de emprego próprio ou de familiares são ações promovidas pela indústria e consideradas como compensações relevantes pelos cidadãos.

Os diagnósticos e as ações não consideram a complexidade da contaminação, o que pode ser ilustrado em vários aspetos específicos.

Os pareceres técnico-científicos (relatórios e estudos de impacto ambiental) foram produzidos para o diagnóstico da contaminação ambiental e para apenas servirem de prova de existência ou, em alguns momentos, para reforçar o discurso da menor (ou nenhuma) relevância dos problemas. Em Estarreja, os documentos produzidos elegeram a tecnologia do aterro controlado como a mais adequada para resolução do problema dos resíduos tóxicos acondicionados a céu aberto. Em CM, a informação foi produzida em decorrência da necessidade de estruturar medidas emergenciais para a mitigação da contaminação ambiental. A saúde da população é interpretada apenas como “ausência de doença” e sua relação complexa com o meio ambiente e com os outros fatores económicos, sociais e culturais existentes no contexto não é levada em conta. Os dois casos apresentam diferenças na abordagem e no tratamento do tema da saúde, mas o resultado final é semelhante: a saúde é uma questão ausente em Estarreja, e em CM é tratada como um assunto periférico. No caso português, há ausência de estudos aprofundados na área. As únicas avaliações existentes são limitadas e apontam para a necessidade de continuidade, uma recomendação que não foi, contudo, seguida. Não foram tomadas medidas de proteção da saúde da população exposta. Em CM, existem alguns estudos de avaliação do estado de saúde da população e dos efeitos de sua exposição aos contaminantes, mas não foram realizados de forma contínua e sistemática. Concluiu-se pela ausência de uma relação comprovada entre os problemas de saúde e a exposição, não tendo sido tomadas medidas necessárias de proteção da saúde da população exposta ou potencialmente exposta.
As vulnerabilidades institucionais apareceram nos dois casos, apresentando semelhanças e também particularidades. Não há, nos dois casos de contaminação, uma prestação de contas sobre os diagnósticos efetuados, e grande parte da informação produzida não é pública. Conforme discutido anteriormente, existe um processo simultâneo de invisibilização e agravamento das várias componentes das incertezas apresentadas (técnica, metodológica, expistemológica, societal), o que se articula, por vezes, com um processo de deliberada ocultação tanto das incertezas, como da gravidade potencial do problema por parte de instituições e de atores envolvidos nas origens da contaminação. A incerteza é utilizada apenas como uma expressão de desconhecimento, que o desenvolvimento da C\&T com o tempo irá colmatar. Em Estarreja, a população não teve acesso aos estudos realizados para o diagnóstico ambiental. Apenas os estudos de impacto ambiental para alteração dos processos industriais, que têm um período de consulta pública obrigatória por lei, foram publicitados, mas somente por meio das formas legais previstas, como o anúncio em jornais e na internet, o que não é uma forma efetiva de chamar a população afetada para participar das discussões sobre os resultados e as implicações dos estudos. Em CM, houve apresentação de alguns pareceres produzidos às populações, mas, em geral, isso não ocorreu de forma sistemática, nem dentro de prazos razoáveis. Os resultados apresentados pelos pareceres relacionados ao campo da saúde foram entregues tardiamente e foram pouco discutidos com os afetados.

É possível elencar alguns aspetos gerais agravadores das vulnerabilidades institucionais. Há, nos dois países, políticas públicas insuficientes para atuar sobre as áreas contaminadas e uma fraca atuação dos comités e dos fóruns de discussão existentes. As atividades de fiscalização do cumprimento das medidas e das ações previstas para confrontar os problemas são deficientes e não há investigação da atuação inadequada das instituições. Em Estarreja, o poder económico das empresas poluidoras, que se relaciona ao emprego e ao desenvolvimento local, é um aspeto que direciona e condiciona as ações institucionais. Em CM, o poluidor e remediador da contaminação é o MS, criando-se assim um confli- 
to de interesses dentro e fora da própria instituição. Este aspeto é de grande importância, já que quando o poluidor é uma empresa do setor público e estatal, e no caso do próprio setor saúde, há dificuldades de serem assumidas responsabilidades e impostas sanções no contexto brasileiro.

Há também elementos diferenciados nos contextos dos dois países que agravam as vulnerabilidades institucionais. No caso de Portugal, merecem ser destacados alguns aspetos. O tema dos acidentes industriais graves é pouco abordado num polo químico com risco elevado e o assunto é tratado apenas através de procedimentos burocráticos e rotinas internas das instituições, perpetuando-se um ocultamento e invisibilização desses eventos, que poderiam ser um "motor" para uma atuação institucional mais permanente. 0 fator ambiental não é, por sua vez, considerado central e decisivo na abordagem dos problemas de saúde, nem no que diz respeito às políticas públicas e da estruturação da própria área da saúde pública no país, pois a área tende a ser exclusiva dos profissionais responsáveis pelos cuidados de saúde. A dependência económica na relação entre as instituições locais e as empresas é um aspeto central que dificulta a atuação institucional. Há, também, a falta de uma denúncia pública que as obrigue a atuar, seja por parte da mídia, seja por meio de protestos e mobilizações de cidadãos, movimentos e de associações, o que também contribui para agravar as vulnerabilidades. Não há uma instituição com o papel de defesa dos direitos difusos da sociedade, como o Ministério Público ${ }^{20}$ no Brasil. A UE realiza um controlo externo, sem comprometimento real das indústrias e dos atores locais, o que contribui de forma perversa para sua desresponsabilização, evitando que sejam reconhecidos os conflitos existentes sobre os problemas (entre instituições e com os cidadãos) e promovendo uma resolução das questões pontualmente e no curto prazo (exemplo da construção do aterro para resíduos perigosos).

No caso brasileiro, outros elementos específicos agravadores das situações de vulnerabilidade se destacam. A propriedade da terra e a qualidade de vida dos afetados não são parte dos processos decisórios que abordam a contaminação, mas são centrais à complexidade do caso. Já os mecanismos de participação existentes - conselhos de saúde e conselhos estaduais e federal de ambiente - não tiveram relevância no tratamento do caso para abertura do debate e reforço das posições dos afetados. 0 MP tem sua atuação baseada na defesa do bem comum, no desrespeito do direito dos residentes a uma vida saudável, mas acaba funcionando como um promotor de ações que visam à resolução do problema ambiental. Um número grande de instituições de várias esferas - municipais, estaduais e federais - e vinculadas aos diferentes poderes - judicial, executivo e legislativo - são responsáveis por diferentes aspetos do problema, o que gera fragmentação de responsabilidades e ações. Sua localização é fisicamente afastada do local contaminado, e acabam não conhecendo a realidade local. As diversas mudanças ocorridas nas instituições responsáveis pelos diagnósticos também prejudicaram a atuação institucional.

Nos dois casos, as comunidades impactadas estão pouco organizadas e enfrentam obstáculos e constrangimentos para atuar no espaço público, havendo vulnerabilidades populacionais acentuadas. Os cidadãos agem individualmente, na defesa de seu interesse próprio, de sua qualidade de vida e de sua família. Em ambos os casos, constituíram-se ou manifestaram-se, em certas ocasiões, atores coletivos, mas não conduziram a uma ação continuada. Não há, até os dias de hoje nos casos em questão ${ }^{21}$, ação coletiva e articulação das questões

\footnotetext{
19 Há uma Organização Não Governamental (ONG) local preocupada com questões ambientais, mas tem sua atuação desde os anos 2000 praticamente restrita à participação de um representante no painel consultivo das indústrias.

20 A promoção da legalidade, através de ações no sistema judiciário, é o objetivo do Ministério Público em Portugal. Diferente do Brasil, em que a defesa do bem comum (de que o meio ambiente faz parte) é uma de suas frentes de atuação.

$21 E ́$ importante destacar no Brasil a atuação da Rede Brasileira de Justiça Ambiental. Desde 2002 constitui-se um fórum de partilha de conhecimentos, discussão, mobilização e articulação para formulação de alternativas e potencialização das ações de resistência desenvolvidas por seus membros (movimentos sociais, entidades ambientalistas, ONGs, associações de moradores, sindicatos, pesquisadores universitários e núcleos de instituições de pesquisa/ensino). Em Portugal, existem algumas plataformas com os mesmos objetivos, mas focadas em temas como a luta contra os organismos geneticamente modificados, barragens, aterros sanitários e resíduos tóxicos.
} 
ambientais e de saúde com questões de luta política, por direitos e cidadania, nem uma atuação em rede, articulando movimentos locais com movimentos globais, acentuando ainda mais sua vulnerabilidade para enfrentamento dos problemas. Alguns fatores contribuíram para essa situação: a deflagração da contaminação não ter resultado numa rutura do dia a dia da população, sendo o quotidiano vivido como se a contaminação não existisse; não haver financiamentos disponíveis para contratos de assessoria técnica a realizar pelos afetados e ausência de envolvimento voluntário de peritos engajados com as causas, impossibilitando a produção de pareceres alternativos; os espaços disponíveis para o encontro dos diferentes saberes (fóruns, comités, grupos de trabalho) funcionarem como legitimadores das atividades que geram as externalidades negativas e como uma forma de controle dos afetados e de intensificação das desigualdades; as definições dos problemas a resolver e das agendas de implementação de ações ser determinada pelos responsáveis pela contaminação; a inexistência de canais de comunicação satisfatórios da população com as instituições públicas e a falta de acesso à informação sobre o diagnóstico e os processos decisórios em curso.

\section{Conclusões}

A contaminação química, em áreas onde pessoas vivem e/ou trabalham, é um tema que abrange um amplo leque de atores sociais e de instituições com diferentes competências e funções e de diferentes setores (ambiente, saúde, agricultura, justiça). Faz emergir questões que estão relacionadas à qualidade do ambiente e à saúde das populações, como a poluição do solo, do ar e dos recursos hídricos, a contaminação dos alimentos e dos animais cultivados em ambiente poluído, a contaminação do leite materno, como também questões sociais, como os conflitos pelo uso do solo, a desigualdade social e a violência. Todos esses são aspetos de sua complexidade. As dificuldades da definição do grau, da extensão de contaminação e dos efeitos dos químicos sobre o ambiente e a saúde das populações atingidas são exemplos de incertezas técnicas e metodológicas que dialogam diretamente com a incerteza societal, afetando a confiança e o diálogo entre os diversos atores: as populações (potencialmente) atingidas, as instituições competentes, entre outros.

Em Portugal não existem políticas públicas dirigidas diretamente aos casos de contaminação química. No Brasil, há uma política recente (antigo Vigisolo, atual Sissolo), mas que se tem revelado ineficaz como resposta às demandas existentes e como possível elo de coordenação entre o MS e outras instituições responsáveis pelo tratamento dos problemas de contaminação química (prefeituras, secretarias de saúde, órgãos ambientais, empresas etc.).

As ações institucionais desenvolvidas nos dois países, e especificamente nos dois casos estudados, não têm sido suficientes para dar conta das questões existentes. As populações atingidas não estão organizadas para reivindicar os seus direitos a um ambiente limpo e a uma vida saudável, o que aumenta consideravelmente sua vulnerabilidade diante dos potenciais impactes negativos de atividades produtivas passadas, no caso do Brasil, e passadas e presentes, no caso de Portugal.

Em Cidade dos Meninos e Estarreja, os diferentes atores desenvolvem saberes pertinentes para o conhecimento das situações de contaminação, saberes situados, vinculados a lugares e vivências, e que geram formas específicas de ação (Haraway, 1988), mas que estão também associados a formas particulares de ignorância. Por um lado, os cidadãos normalmente apresentam carência de conhecimentos teóricos sobre os problemas e agem, frequentemente, na defesa de seu interesse próprio, de sua qualidade de vida e de sua família, o que nem sempre coincide com a avaliação dos técnicos. Por outro lado, os cientistas e os técnicos carecem, frequentemente, de conhecimentos práticos vinculados aos contextos em que devem atuar, agindo, muitas vezes, na base do pressuposto da universalidade de seu conhecimento.

Há potencialidades nos dois casos para a geração de ações coletivas no futuro. As experiências quotidianas dos cidadãos em Estarreja - a morte de animais, a dificuldade de plantio, o cheiro forte na água e no ar ou o mal-estar físico de pessoas - e em CM - o cheiro forte na estrada, os casos de deforma- 
ções fetais e abortos espontâneos, os casos de perda de olfato, de alergias, de doenças neurológicas e de câncer - fornecem indicações de que a contaminação química gera consequências graves para a saúde de seres humanos, de animais e de ecossistemas. Esses problemas podem constituir-se como "gatilhos" para ações coletivas, utilizando a bandeira da saúde como forma de definir uma agenda pública de união da questão ambiental à luta pelos direitos e pela justiça, promovendo assim a relação entre riscos ambientais, saúde, democracia e justiça. Também o acesso a terra para cultivo em Portugal e à moradia, no Brasil, poderiam ser outros temas para promoção desta "virada": da ação individual para a ação coletiva e em rede.

\section{Referências}

ACSELRAD, H. Vulnerabilidade, processos e relações. In: FERREIRA, H. S.; LEITE, J. R. M.; BORATTI, L. V. (Org.). Estado de direito ambiental: tendências. 2. ed. Rio de Janeiro: Forense Universitária, 2010. p. 95-103.

ALLEN, B. L. Uneasy alchemy: citizens and experts in Louisiana's chemical corridor dispute. Cambridge: The MIT Press, 2003.

AUYERO, J.; SWISTUN, D. A. Flammable: environmental suffering in an argentine shantytown. Oxford: Oxford University Press, 2009.

BECK, U. Risk society: towards a new modernity. London: Sage Publications, 1992.

BROWN, P.; MIKKELSEN, E. No safe place: toxic wastes, leukemia and community action. Berkeley: University of California Press, 1997.

BRASIL. Áreas contaminadas. São Paulo: Centro de Vigilância Sanitária, 2009. Disponível em: <http://www.cvs.saude.sp.gov.br/apresentacao. asp?te_codigo=14>. Acesso em: 10 ago. 2014.

EDELSTEIN, M. Contaminated communities: coping with residential toxic exposure. Boulder: Westview Press, 2004.

ESCOBAR, A. El lugar de la naturaleza y la naturaleza del lugar: globalización o postdesarrolo? In: LANDER, E. (Org.). La colonialidad del saber: eurocentrismo y ciencias sociales-perspectivas latinoamericanas. Buenos Aires: Consejo Latinoamericano de Ciencias Sociales, 1993. p .113-143.

FERGUSON, C. C. Assessing risks from contaminated sites: policy and practice in 16 European Countries. Land Contamination e Reclamation, London, v. 7, n. 2, p. 33-55, 1999. FERNANDES, L. O. Complexidade, incertezas e vulnerabilidades: estudo de áreas contaminadas habitadas em Portugal e no Brasil. 2010. Tese (Doutorado em Sociologia) - Faculdade de Economia da Universidade de Coimbra, Coimbra, 2011.

FUNTOWICZ, S.; RAVETZ, J. Science for the postnormal age. Futures, London, v. 7, n. 25, p. 739-755, 1993.

HAMILTON, J.; VISCUSI, K. Calculating risks-the spatial and political dimensions of hazardous waste policy. London: MIT Press, 1999.

HARAWAY, D. Situated knowledges: the science question in feminism and the privilege of partial perspective. Feminist Studies, Maryland, v. 3, n. 14, p. 575-99, 1988.

LEVINE, A. G. Love canal: science, politics and people. New York: D. C. Heath and Company, 1982.

LEVINS, R.; LOPEZ, C. Toward an ecosocial view of health. International Journal of Health Services, New York, v. 2, n. 29, p. 261-93, 1999.

MAIS de 2,1 milhões vivem em áreas de risco de contaminação. Portal da Saúde, Brasília, DF, 9 dez. 2009. Disponível em: <http://portalsaude. saude.gov.br/index.php/cidadao/principal/ agencia-saude/noticias-anteriores-agenciasaude/3998>. Acesso em: 15 ago. 2014.

PANAGOS, P. et al. Contaminated sites in Europe: review of the current situation based on data collected through a european network. Journal of Environmental and Public Health, Brussels, ID 158764, 2013. Disponível em: <http://dx.doi. org/10.1155/2013/158764>. Acesso em: 10 ago. 2014. PORTO, M. F. S. Uma ecologia política dos riscos: princípios para integrarmos o local e o global na 
promoção da saúde e da justiça ambiental. 2. ed. Rio de Janeiro: Fiocruz, 2012.

PORTO, M. F. S. Complexidade, processos de vulnerabilização e justiça ambiental: um ensaio de epistemologia política. Revista Crítica de Ciências Sociais, Coimbra, n. 93, jun; 2011. Disponível em: <http://rccs.revues.org/133>. Acesso em: 10 ago. 2014.

PORTO, M. F. S.; FERNANDES, L. O.

Understanding risks in socially vulnerable contexts: the case of burning wastes in cement kilns in Brazil. Safety Science, Riverport Lane, v. 3, n. 44, p. 241-257, 2006.

SÁNCHEZ, L. E. Revitalização de áreas contaminadas. In: MOERI, E.; COELHO, R.; MARKER, A. (Ed.). Remediação e revitalização de áreas contaminadas: aspetos técnicos, legais e financeiros. São Paulo: Signus, 2004. p. 79-9o.
SHIVA, V. Resources. In: SACHS, W. (Org.). The development dictionary: a guide to knowledge as power. London: Zed Books, 1992. p. 206-218.

STEINGRABER, S. Living downstream: an ecologist looks at cancer and the environment. London: Virago Press, 1998.

THORNTON, J. Pandora's poison: chlorine, health and a new environmental strategy. Cambridge: MIT Press, 2000.

VAN DER SLUIJS, J. et al. Combining quantitative and qualitative measures of uncertainty in model based environmental assessment: the NUSAP system. Risk Analysis, Malden, v. 2, n. 25, p. 481492, 2005 .

WINCHESTER, P. Power, choice and vulnerability: a case study in disaster management in south India. London: James \& James, 1992.

WYNNE, B. Risk management and hazardous waste-implementation and dialectics of credibility. Berlin: Springer-Verlag, 1987.

\section{Contribuição dos autores}

Fernandes organizou a informação para o artigo (proveniente de sua tese de doutorado) e atualizou a discussão teórica; Arriscado e Porto revisaram o texto e deram novos contributos para a discussão teórica e articulação das ideias (ambos acompanharam o trabalho de pesquisa durante todos os anos de trabalho do doutorado).

Recebido: 02/06/2015

Reapresentado: 03/09/2015

Aprovado: 22/09/2015 